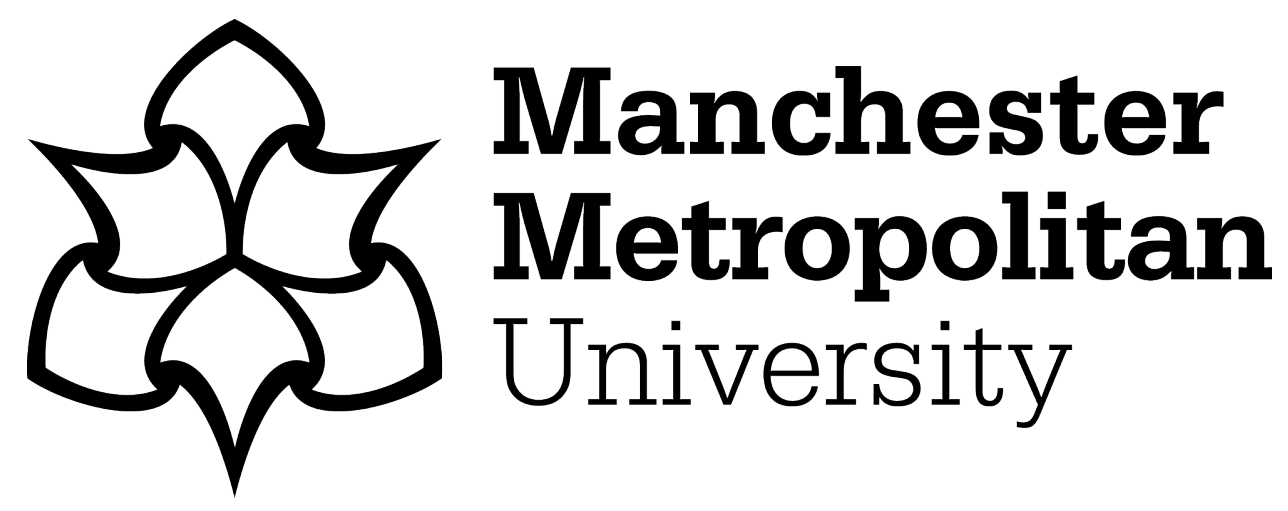

Hearn, Jasmine ORCID logoORCID: https://orcid.org/0000-0001-5988-5278, Dewji, Mohamed, Stocker, Claire and Simons, Greg (2019) Patient-centered medical education: a proposed definition. Medical Teacher, 41 (8). pp. 934938. ISSN 0142-159X

Downloaded from: https://e-space.mmu.ac.uk/622992/

Version: Accepted Version

Publisher: Taylor \& Francis

DOI: https://doi.org/10.1080/0142159x.2019.1597258

Please cite the published version 
Running Head: Patient-Centred Medical Education

1 This is a post-peer-review, pre-copyedit version of an article published in Medical Teacher.

2 The final authenticated version is available online at:

3 https://www.tandfonline.com/doi/full/10.1080/0142159X.2019.1597258?scroll=top\&needAc

4 cess $=$ true 
Running Head: Patient-Centred Medical Education

5

8

\title{
Patient-centred medical education: A proposed definition
}

Key words: undergraduate medical education; patient-centred care; patient involvement; service users

\section{Abstract}

Multiple papers have been presented to define patient-centred care, with regulatory bodies such as the General Medical Council mapping this in their professional standards. Educational institutions clearly value instilling appreciation of patient-centredness in medical training, and attempts have been made to make medical education more patient-centred in practice. Such attempts are often limited to expert patients sharing personal stories, and public involvement in teaching. Despite the drive towards patient-centred care and medical education, there has been no attempt to formally define what patient-centred medical education is and what it means to medical educators globally. This paper proposes a definition of patientcentred medical education that is about the patients, with the patients, and for the patients, to ensure current and future doctors remain sensitive to all of the needs of the people they care for. This should be considered at both the micro and macro community levels.
\end{abstract}




\section{Patient-Centred Care}

Patient-centredness is increasingly prioritised across medical schools and medical practice, with the General Medical Council (GMC) standards for Promoting Excellence in Medical Education (2015) emphasising its importance in the UK. However, patient-centredness may be poorly understood and there have been few attempts to formally define patient-centred medical education. This underscores the key aim of the present paper.

In order to begin to define patient-centred medical education, it is important to draw on our current understanding of patient-centred care. Few common definitions can be found across the literature (Kitson, 2013), but three core themes can be identified: patient participation and involvement, the relationship between the patient and the healthcare professional, and the context in which health care is delivered. That is, health care is delivered in a way that is meaningful and valuable to the individual patient. It has also been recognised that the best way of measuring patient-centredness is an assessment made by the patients themselves, with evidence (Little et al., 2001) highlighting that patients want patient-centred care which (a) explores the patients' main reason for the visit, concerns, and need for information; $(b)$ seeks an integrated understanding of the patients' world - that is, their whole person, emotional needs, and life issues; $(c)$ finds common ground on what the problem is and mutually agrees on management; $(d)$ enhances prevention and health promotion; and $(e)$ enhances the continuing relationship between the patient and the doctor.

Patient-centred clinical practice is a holistic concept, in which components interact and unite in a unique way in each patient-doctor encounter, implying the requirement for doctors to be flexible in their approach to each patient. This is supported by the recent White Paper published by the Department of Health (2012), which set out the UK government's vision of a National Health Service (NHS) that puts patients first; where 'no decision about me, without me' is to be the norm. This has led to agreement that medical education is required to support the development of doctors who can effectively partner with patients, families, and other healthcare disciplines to foster optimal patient outcomes (American College of Physicians, 2018). For this approach to become embedded in doctors' daily practice, it is imperative that deep appreciation of the utility of a strong partnership and improving/managing health through the patient's eyes is fostered from the outset in medical training.

\section{Patient-Centred Medical Education}

So as to illuminate the current understanding of patient-centred medical education, a systematic approach was used to search MEDLINE in May 2018 to identify any publications that 
described patient-centred medical education. This included the following search strategy: 'patient-centred' OR 'patient-centered' AND 'medical education'. The search was limited to results from 2000 to 2018 and to full-text articles. 123 articles were identified, at which point titles and abstracts were screened and any referring to patient-centred care only were removed. A final eight articles were identified that made reference to patient-centred medical education (see Figure 1). These are discussed further below.

***INSERT FIGURE 1 HERE***

All of the articles identified made reference to patient-centred medical education, with many attempting to describe what patient-centred medical education looks like in practice. For example, 'patient-centred learning' has been described as focus on patients who have medical problems or are being seen in practice for the purpose of health maintenance, particularly those seen multiple times over the course of the students' training (Smith, Cookson, McKendree, and Harden, 2001; Walters and Brooks, 2016. There is a need for community-based learning (Howe, 2001) with a call for education to make use of the developing digital technologies that can contribute to patient- centred care (Glick and Moore, 2001).

However, no published work could be found that has formally and holistically integrated patient-centredness into the entire undergraduate medical curriculum. This may lead to a lack of evidence and guiding structures upon which to develop and evaluate undergraduate medical curricula. To progress, we need a working definition of this concept and our proposed definition is:

'Patient-centred medical education is about the patients, with the patients, and for the patients, to ensure current and future doctors remain sensitive to all of the needs of the people for whom they care.'

There have been calls to make medical education more patient-centred. Previous attempts to integrate patient-centredness into medical education have been made by Barr, Ogden and Rooney (2014), who have implied delivering this remit by introducing senior medical students to patient-partner-programmes. They report on students meeting with a patient partner with a chronic illness to hear their narrative and practice consultation skills. Others initiatives include 
the use of expert patients in teaching and assessment (Towle \& Godolphin, 2013), and contributions from the community in student selection, and curriculum development, implementation and evaluation (Spencer \& McKimm, 2010). The Ladder of Patient Involvement (Tew, Gell, \& Foster, 2004) denotes five levels of patient involvement in medical education, ranging from 'no involvement' (level 1) through to 'systemic and strategic involvement in all key decisions' and 'consistent participation in teaching sessions' (level 5: partnership) in which patients are valued as peers, recognize themselves as such and are made aware in detail of the improved education and how this impacts back on the patients themselves. However, the primary focus of medical education and discussions remain focused on what the trainee is required to do in order to reach a diagnosis and effectively treat the condition. Such discussions invariably stop short of addressing how the medical professional can best understand the social circumstances surrounding the patient, and the holistic impact that a diagnosis has on someone's life. This underscores the need for a central definition of patient-centred medical education upon which medical curricula can develop to best meet those needs and mitigate the impacts. The aspiration has to be that upon graduation, students have developed the commitment and skills to provide patient-centred approaches in their future career.

\section{About the Patients}

This element of the definition principally describes the local morbidity and mortality within the social and cultural context of the patients in their environment, acknowledging that patients do not exist in isolation, but are in communities. The base envelope covers the local causes of morbidity and mortality; equally factors such as the wider family, socioeconomic, ethnic and other pertinent groupings and circumstances have a significant impact on health and health equity (Braveman, 2014), and should be considered in educational settings. Traditionally educational publications have been focussed on long term conditions with their impact on multi-morbidity. This may well be due to the relative focus in a developed health system. In a developing country, greater focus may be placed on communicable diseases and macro factors affecting the health of the patients as a whole. Medical curricula are already themed on mental and physical disease, and regulatory guidance encourages this approach to consider the wider cultural and social backgrounds (GMC, 2018). Whilst this inspires a broader understanding 
and learning of the health issues for the patient population, the challenge is for curricula to demonstrate an analysis of that population group's needs and is then adaptive as those needs develop.

\section{With the Patients}

In addition to the wider sociocultural context in which the patient lives, their unique, individual health and illness context balanced with the communication and consultation challenges presented are just as important to consider, when studying the diagnostic challenge. Indeed, patients are not simply collections of organ systems requiring pharmacological intervention, but present as humans with historical and cultural narratives, values, goals, concerns, and sexual and relational functioning. As such, the GMC advocate that Medical Schools should provide students with opportunities for early patient contact that increases as the student progresses, to follow patients through care pathways, and to learn about the role of the aforementioned narratives and values in health and health care (GMC, 2015). Any curriculum that places emphasis on these, and values the patient as an integral partner within the curriculum, is anticipated to ultimately yield more successful outcomes in teaching and learning (GMC, 2011).

Such integration will be diverse, dependent on the local sociocultural context and will develop over time as the population base changes and the trainee's expertise matures. This should be recognised in curricula, an endeavour undertaken using a complexity model approach at our School. Here, students are taught to approach clinical problems with their physical, mental and social dimensions in their entirety in order to achieve a pragmatic solution that fits the individual patient's context. This is done by taking account of this clinical complexity and breaking it down into constituent parts which then inform the curriculum. As such, clinical problems that students encounter at the start of the curriculum begin relatively simply, including single morbidity patients. As they progress through the curriculum, students are exposed to clinical problems that increase in therapeutic, diagnostic, and psychosocial complexity, such that their appreciation of patient-centredness develops appropriately and in accordance with their clinical knowledge. The complexity model will need further discussion as the debate and definition of patient centredness matures.

\section{For the Patients}

The definition proposed above draws on the quote by Abraham Lincoln: 'Government of the people, by the people, for the people, shall not perish from the Earth'. Just as Mr Lincoln 
was keen to break the link between aristocracy and government, perhaps now is the appropriate time to acknowledge that medical education in general, and undergraduate medical education in particular, has for too long been dominated by a western, first-world perspective. It is therefore proposed that governance of medical education requires input from the patients who will be served by tomorrow's doctors at every level. This naturally requires the involvement of patients in medical education, who can act as a powerful vehicle to provide insight from the patient perspective as to where educational priorities should be placed and whether desired attitudes are being effectively developed and integrated into students' daily practice. However, this requires that patient and public involvement moves beyond tokenistic inclusion on Boards, such that patients are placed at the centre of medical education, rather than on the periphery. Their involvement should, move towards holistic inclusion in the selection of medical students, curriculum development, teaching, assessment, feedback, and quality assurance and governance. Caring for, and improving the health of, patients is at the heart of what it is to be a doctor and should therefore be at the heart of medical education. Holding this, and other vocational attitudes and values, is fundamental to the professionalism that any medical teaching organisation aspires to engender.

\section{The role of patient-centred education in teaching professionalism}

The essence of this definition of patient-centredness has been adopted by the Academy of Medical Educators (AoME, 2017). The AoME describe five core values of medical practice, each of which is underpinned by professionalism and ethical values (see Figure 4). Through engagement with assessments of professionalism (e.g. via revalidation by regulatory bodies and personal reflection), students and practitioners can demonstrate commitment to patientcentred care and continued patient-centred education and development (Phelps \& Dalton, 2013). However, demonstration of and commitment to professionalism is most effectively developed through receipt of feedback, which can enhance deep learning and personal integration of professionalism (Papadakis et al, 2001). Students often receive feedback regarding clinical exposure from medical practitioners, patients and their peers as part of their ongoing professional development planning discussions, thereby demonstrating a patientcentred approach to learning in the context of professionalism. Reflection on patient feedback can be recorded by educators, but also, and often more efficiently, by students themselves (in keeping with the constructivist learning style). Students can reliably evaluate their peers 
(Arnold, 1981) and peer-rating forms have high inter-assessor concordance when measuring professional behaviour (Davis and Inamdar, 1988). This form of reflection on patient feedback is especially desirable for professionalism training considering that peer-assessment facilitates the professional attributes of self-regulation and accountability (Leach, 2002). Moreover, patient feedback on these attributes is integral to the regulatory concerns and fitness to practise processes that feed back to students. Likewise, patients need to be made aware of the importance of their input and both theoretically and practically and the benefits that arise. This reinforces the importance of patient-centred approaches in medical education and the alignment of professionalism training to be about the patients, with the patients, and for the patients is integral in supporting students to align their professional identity with a professional and patient-centred focus.

***INSERT FIGURE 2 HERE***

\section{The Future of Patient-Centred Medical Education}

There is no widely accepted definition of patient-centred medical education. We have endeavoured to propose a definition in this paper, which encapsulates an educational approach that is about the patients (considering local demographics and wider sociocultural factors that influence health), with the patients (in view of their unique and individual historical, relational, and cultural narratives), and for the patients (who are holistically integrated into the centre of medical education).

The proposal within the paper is intended to invite wider debate on what it means for medical education to be patient-centred. It is envisaged that, if our proposed definition is accepted in principle then measurable criteria could be developed against which students and doctors as well as their institutions could be assessed in terms of their degree of patientcentredness in their approach to education and learning. The three criteria, with the patients, for the patients, and about the patients also need to be understood within the micro and macro communities they represent. The concept is transferable across different geographies and cultures with respect to the changing nature of what patient-centredness would entail within those populations. It then follows that the teaching within those schools needs to be adaptive to the local demographic. We would further propose that aggregated and appropriate 
assessments of students' patient-centredness are made regularly throughout curricula that wish to foster this value. Indeed, future work would focus upon the development of valid and reliable measures of patient-centredness that are piloted in a variety of curricula approaches. Such an assessment measure should provide actionable feedback to students, such that they can achieve patient-centred care, and to medical schools, such that they are delivering holistic and integrated patient-centred medical education.

We look to this paper inviting future discussions of what patient-centred medical education is and means to medical educators globally, and we hope that all of those involved in healthcare (patients, families, doctors, politicians, commentators and health systems) will be involved in such discussions. We envisage partnerships to look at different themes which may cover disease profiles, cultural awareness, resource implications, traditional models, national and international transferability, self-care and tiered levels of education amongst others. The active participation of patients, medical students, clinicians, and medical educators alike will undoubtedly progress this discussion and ensure that future definitions and attempts to provide patient-centred medical education are aligned with their perspectives and values.

\section{Acknowledgements}

The authors would like to thank Prof. Stewart Petersen and Dr Kenny Langlands for kindly reviewing earlier versions of this manuscript. We would also like to thank our expert patient representatives, Graeme Johnston and Lilia Bogle, for their insights and support in conceptualising the proposed definition. 
Running Head: Patient-Centred Medical Education

\section{References}

Academy of Medical Educators. Accessed $7^{\text {th }}$ December 2017, from: www.medicaleducators.org

American Academy of Family Physicians, American Academy of Pediatrics, American College of Physicians, American Osteopathic Association. Joint principles for the medical education of physicians as preparation for practice in the patient-centered medical home. 2010. Accessed 17 $17^{\text {th }}$ May 2018, from: www.acponline.org/running _practice/delivery_and_payment_models/pcmh/understanding/educ-joint principles.pdf

Arnold, L., Willoughby, L., Calkins, V., Gammon, L. and Eberhart, G. (1981). Use of peer evaluation in the assessment of medical students. Med Educ. 56:35 - 42.

Barr, J., Ogden, K., \& Rooney, K. (2014). Committing to patient-centred medical education. Clin Teach. 11:503-506.

Braveman, P. (2014). What is health equity: And how does a life-course approach take us further toward it? Matern Child Health J. 18:366-372.

Davis, J. K. and Inamdar, S. (1988). Use of peer ratings in a pediatric residency. Med Educ. 63:647-649.

Department of Health. (2012). Liberating the NHS: No decision about me, without me. Government response to the consultation. Accessed $18^{\text {th }}$ May 2018, from https://assets.publishing.service.gov.uk/government/uploads/system/uploads/attachme nt data/file/216980/Liberating-the-NHS-No-decision-about-me-without-meGovernment-response.pdf

General Medical Council (2011). Patient and public involvement in undergraduate medical education. Accessed $4^{\text {th }}$ July, 2018 from https://www.gmc-uk.org//media/documents/Patient_and_public_involvement_in_undergraduate_medical_educ ation_guidance_0815.pdf_56438926.pdf

General Medical Council (2015). Promoting Excellence: Standards for Medical Education and Training. Accessed $4^{\text {th }} \quad$ July, 2018 from https://www.gmc-uk.org//media/documents/promoting-excellence-standards-for-medical-education-andtraining-0715_pdf-61939165.pdf

General Medical Council (2018). Outcomes for Graduates. Accessed $4^{\text {th }}$ July, 2018 from https://www.gmc-uk.org/-/media/documents/dc11326-outcomes-for-graduates2018_pdf-75040796.pdf 
Glick, T. H. \& Moore, G. T. (2001). Time to learn: the outlook for renewal of patient-centred education in the digital age. Med Educ. 35(5):505-9.

Howe, A. (2001). Patient-centred medicine through student-centred teaching: a student perspective on the key impacts of community- based learning in undergraduate medical education. Med Educ. 35(7):666-72.

Kitson, A., Marshall, A., Bassett, K., \& Zeitz, K. (2013). What are the core elements of patientcentred care? A narrative review and synthesis of the literature from health policy, medicine and nursing. J Adv Nurs. 69(1):4-5.

Little, P., Everitt, H., Williamson, I., Warner, G., Moore, M., Gould, C., Ferrier, K., \& Payne, S. (2001). Preferences of patients for patient centred approach to consultation in primary care: observational study. BMJ. 322:468.

Leach, D. C. (2004). Professionalism: The formation of physicians. Am J Bioeth. 4:11 - 12.

O’Hanlon, C. E. \& Harvey, M. (2017). Doing More with Less: Lessons from Cuba's Health

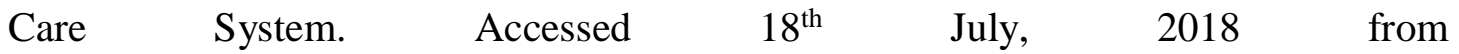
https://www.rand.org/blog/2017/10/doing-more-with-less-lessons-from-cubas-healthcare.html

Papadakis, M., Loeser, H., Healy, K. (2001). Early detection and evaluation of professionalism deficiencies in medical students: One school's approach. Acad. Med. 76: $1100-1106$.

Phelps, G. \& Dalton, S. (2013). Demonstrable professionalism: linking patient-centred care and revalidation. Intern Med J. 43:1254-1256.

Smith, S. R., Cookson, J., McKendree, J., \& Harden, R. M. (2007). Patient-centred learningback to the future. Med Teach. 29(1):33-7.

Spencer, J. \& McKimm, J. (2010). Patient involvement in medical education. In Understanding Medical Education: Evidence, Theory and Practice. Edited by: Swanwick T. Oxford: Wiley-Blackwell, 181-194.

Tew, J., Gell, C. \& Foster, S. (2004). Learning from Experience: involving service users and carers in mental health education and training. Mental Health in Higher Education/NIMHE West Midlands/Trent WDC, York.

Towle, A. \& Godolphin, W. (2013). Patient involvement in medical education. In Oxford Textbook of Medical Education. Ed. Walsh, K. Oxford: Oxford University Press.

Walters, L. \& Brooks, K. (2016). Integration, continuity and longitudinality: the 'what' that makes patient-centred learning in clinical clerkships. Med Educ. 50(9):889-91. 
Running Head: Patient-Centred Medical Education

312

313

314

315

316

317

318

319

320

Total articles identified $(\mathrm{n}=$

123)

Excluded $(\mathrm{N}=115)$

Not referring to patient-centred

medical education $(n=115)$

321

322

Figure 1. Literature search results.

323 
327 Figure 2. Adapted from the core values of teaching professionalism (Academy of Medical 328 Educators, 2017). 